\title{
Jejunal inflammatory granuloma: a complication of direct percutaneous endoscopic jejunostomy
}

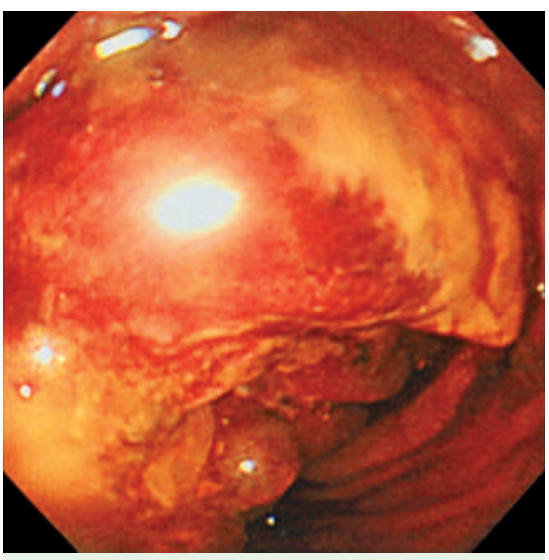

Figure 1 Transjejunostomal endoscopic view showing an irregular jejunal tumor on the wall opposite the jejunocutaneous fistula.

A 75-year-old woman was referred to our hospital for follow-up treatment after an intracerebral bleed on 5 February 2002. We placed a percutaneous endoscopic gastrostomy (PEG) on 5 March 2002 for enteral feeding. She developed frequent vomiting of the nutrients administered through the PEG tube 26 months after PEG placement. We tried gastric motility stimulant drugs, but these were ineffective, and on 21 June 2004 we performed a direct percutaneous endoscopic jejunostomy (D-PEJ). A one-step button (Boston Scientific, Natick, Massachusetts, USA) was placed approximately $15 \mathrm{~cm}$ distal to the ligament of Treitz, according to methods described previously [1].

Seventeen months after the D-PEJ placement, she suddenly vomited gastric juices and the nutrients administered through the D-PEJ, and this was complicated by the development of aspiration pneumonia. A small-caliber endoscope (GIF XP-240; Olympus Optical Co. Ltd., Tokyo, Japan) was inserted through the jejunocutaneous tract, and we found a round, irregular-shaped tumor on the opposite wall of the fistula ( Figure 1). A biopsy specimen from the tumor revealed inflammatory granulation tissue infiltrated with neutrophils ( $\bullet$ Figure 2 ).

Adverse events reported to be associated with D-PEJ to date are bleeding, colonic perforation, abdominal wall abscess, jejunal volvulus, aspiration, persistent enterocutaneous fistulas, peristomal leakage

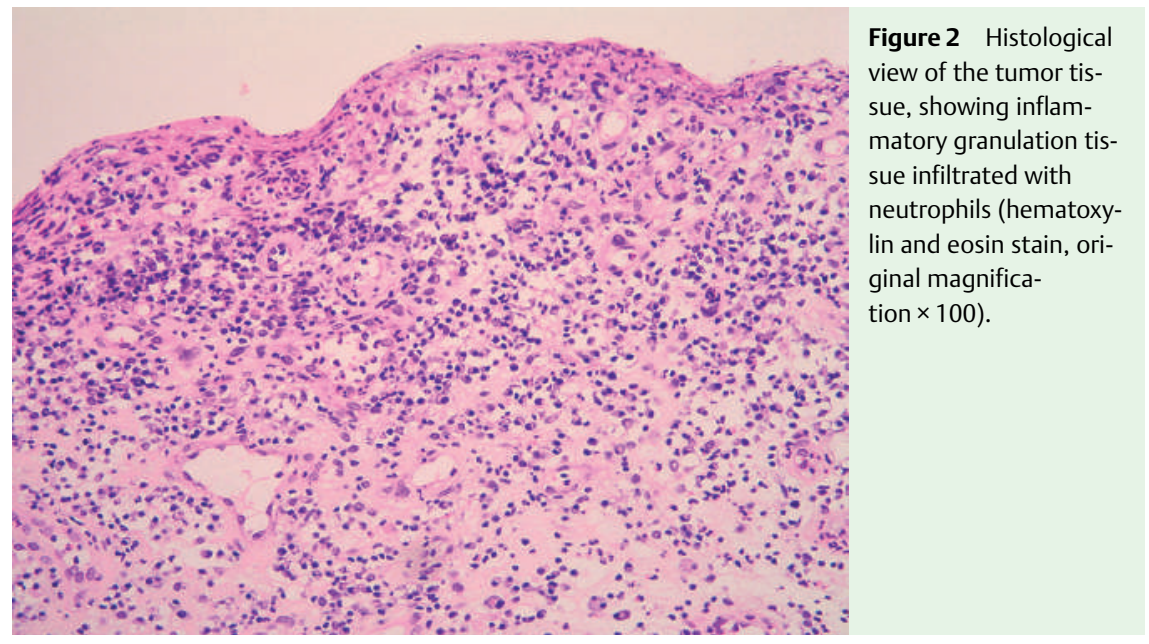

and infection, and jejunal ulcer [2]. This is the first case report of intrajejunal granuloma formation after D-PEJ. Peristomal granulation occurs frequently after PEG. Intragastric pseudotumoral gastric mucosa or bumper-related polyps have also been reported previously $[3,4]$. These tumors are thought to be caused by repeated stimulation of the gastric mucosa by the inner bumper after PEG. Histological examinatin of the tumors usually reveals hyperplasia of the foveolar epithelium of the gastric mucosa, but occasionally inflammatory granulation is found [4]. In this case, the top of the bumper was touching the opposite wall of the fistula and caused inflammation. Intrajejunal granuloma should be noted as a potential adverse effect of D-PEJ.

Endoscopy_UCTN_Code_CPL_1AH_2AI

\section{S. Nishiwaki, Y. Shirakami, T. Hayashi, \\ K. Saitoh}

Department of Internal Medicine, Nishimino Kousei Hospital, Gifu, Japan

\section{References}

1 Nishiwaki S, Araki H, Shirakami Y et al. One step button placement of direct percutaneous endoscopic jejunostomy using transgastrostomic endoscopy [abstract]. Gastrointest Endosc 2006; 63: AB171

2 Maple JT, Petersen BT, Baron TH et al. Direct percutaneous endoscopic jejunostomy: outcomes in 307 consecutive attempts. Am J Gastroenterol 2005; 100: 2681 - 2688

3 Segal D, Michaud L, Guimber D et al. Late-onset complications of percutaneous endoscopic gastrostomy in children. J Pediatr Gastroenterol Nutr 2001; 33: 495-500

4 Nishiwaki S, Araki H, Shirakami Yet al. Endoscopic features of bumper related polyps following percutaneous endoscopic gastrostomy (PEG) [in Japanese, English abstract]. Gastroenterol Endosc 2006; 48: $23-30$

Bibliography

DOI $10.1055 / \mathrm{s}-2007-966154$

Endoscopy 2007; 39: E116

(c) Georg Thieme Verlag KG Stuttgart · New York . ISSN 0013-726X

\section{Corresponding author}

\section{S. Nishiwaki, MD}

Department of Internal Medicine Nishimino Kousei Hospital 986 Oshikoshi Yoro-cho, Yoro-gun Gifu 503-1394

Japan

Fax: +81-584-32-2856

wakky@nishimino.gfkosei.or.jp 